\title{
Parathyroid adenoma, Pituitary Macroadenoma and Hypergastrinaemia in a patient with negative genetic testing for Multiple Endocrine Neoplasia Type 1: a mere coincidence?
}

\section{Dr. AR Arefin, Dr. C Hay.}

email: rashadarefin@doctors.org.uk

University Hospitals of Morecambe Bay NHS Foundation Trust, Cumbria, United Kingdom.

Cumbria Partnership NHS Foundations Trust, Cumbria, United Kingdom.

\begin{tabular}{|c|}
\hline $\begin{array}{c}\text { University Hospitals WHS } \\
\text { of Morecambe Bay } \\
\text { NHS Foundation Trust }\end{array}$ \\
\hline
\end{tabular} Cumbria Partnership WHS

\section{Aims}

1. To highlight the main tumour types associated with MEN1 and the lesser associated tumour types.

2. To highlight the different criteria for the diagnosis of MEN1.

3. To address the concept of MEN1 phenocopies.

\section{Introduction}

- Multiple Endocrine Neoplasia Type 1 (MEN1) is a rare, autosomal dominant condition with an estimated prevalence of 1-10/100,000.

- MEN1 is inherited through mutation of the MEN1 gene located on chromosome 11q13.

- MEN1 involves tumour development in two or more endocrine glands associated with the syndrome, in a single patient (see Table 1$)^{1-3}$.
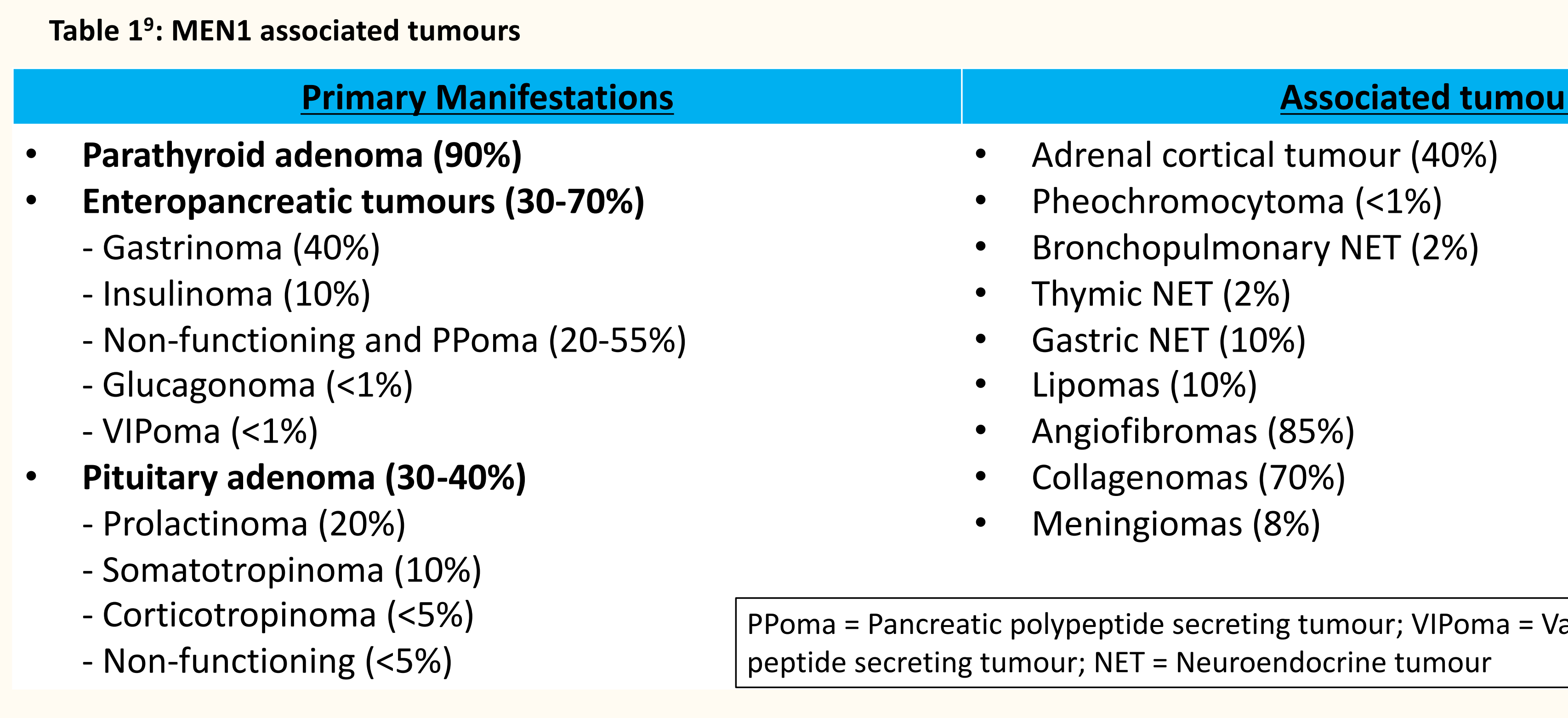

PPoma $=$ Pancreatic polypeptide secreting tumour; VIPoma $=v$ peptide secreting tumour; NET $=$ Neuroendocrine tumour

Lipomas (10\%)

Angiofibromas (85\%)

Collagenomas $(70 \%)$

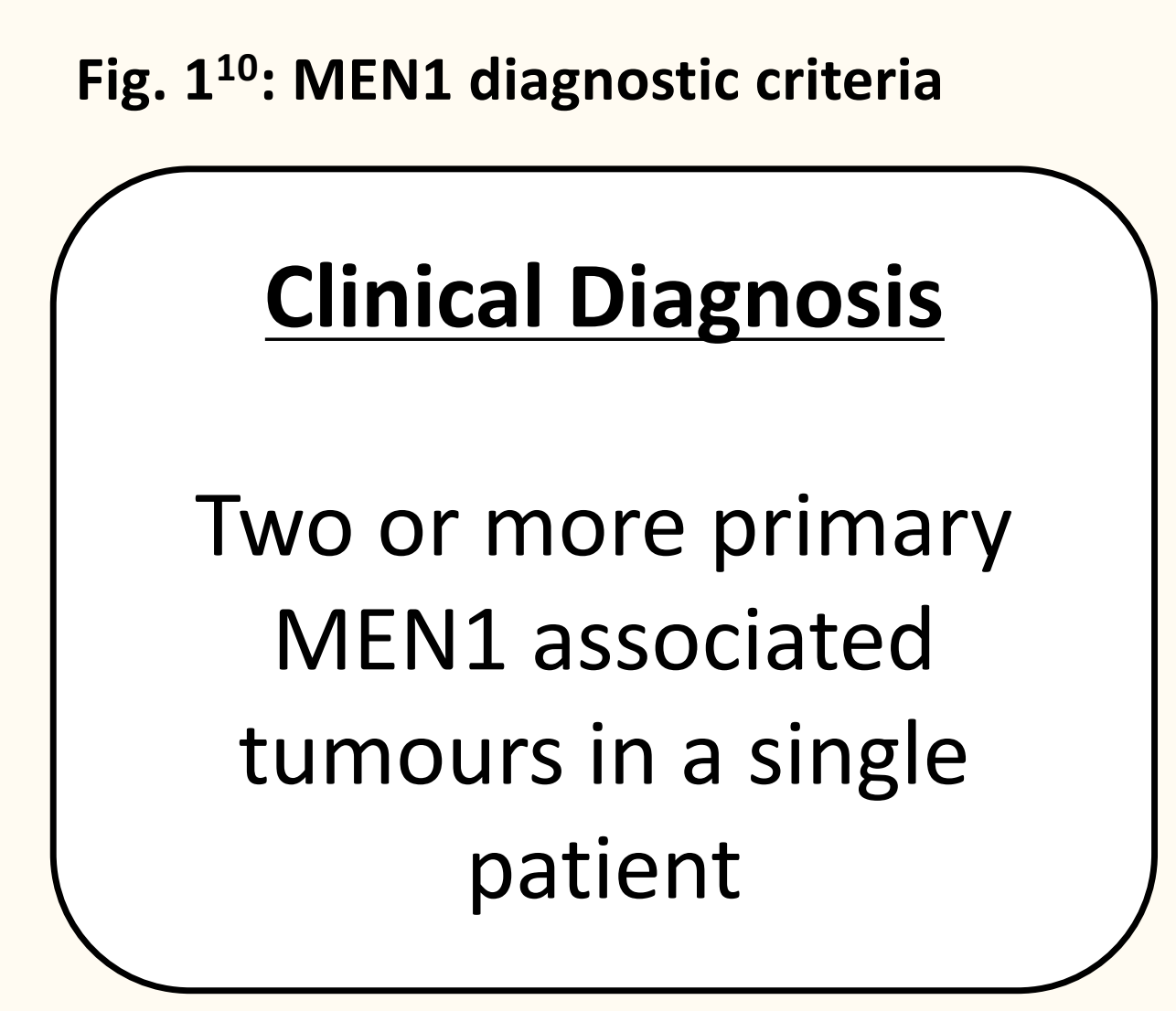
Familial Diagnosis
One MEN1 tumour in a first degree relative of patient with a clinical diagnosis of MEN1

Genetic Diagnosis

Confirmed germline MEN1 mutation - with or without features of tumour development

\section{Case Report}

- A 56 year old lady presented to the endocrinology clinic following an incidental finding of hypercalcaemia (see Figure 2). She was normally fit and well, on no regular medication and had no significant family history.

- Primary hyperparathyroidism was diagnosed. A solitary parathyroid adenoma was identified through parathyroid MIBI Scan. Renal calculi were present on US imaging.

- Her hypercalcaemia progressed and sequelae of uncontrolled hypercalcaemia developed, requiring surgical intervention.

- Unrelated investigation for suspected TIA identified a pituitary mass. MRI imaging revealed an intrasellar pituitary mass. Pituitary function tests confirmed a nonfunctioning pituitary macroadenoma (see Figure 2).

- Presence of two primary MEN1 tumours required further investigation for the syndrome.

- Fasting gut peptide profile showed raised gastrin levels. She denied use of proton pump inhibitors and had no symptoms of hypergastrinaemia. An MRI pancreas and subsequent octreotide scan failed to locate gastrinomas. Genetic analysis did not identify a germline mutation of the MEN1 gene.

Fig. 2: Investigation results

\begin{tabular}{|c|} 
Initial presentation \\
Asymptomatic hypercalcaemia: $\mathrm{Ca}^{2+}=2.77 \mathrm{mmol} / \mathrm{L} ; \mathrm{PTH}=11.9 \mathrm{pmol} / \mathrm{L}$ \\
$24 \mathrm{~h}$ urinary $\mathrm{Ca}^{2+}=7.5 \mathrm{mmol} / 24 \mathrm{~h}(1-7.5)$ \\
USS neck and parathyroid $\mathrm{MIBI}=27 \times 12 \times 10 \mathrm{~mm}$ parathyroid adenoma \\
US renal tract $=9.4 \times 8 \mathrm{~mm}$ calculus in right kidney \\
Renal Profile $=$ normal \\
DEXA scan $=$ normal
\end{tabular}

Diagnosis $=$ Primary hyperparathyroidism

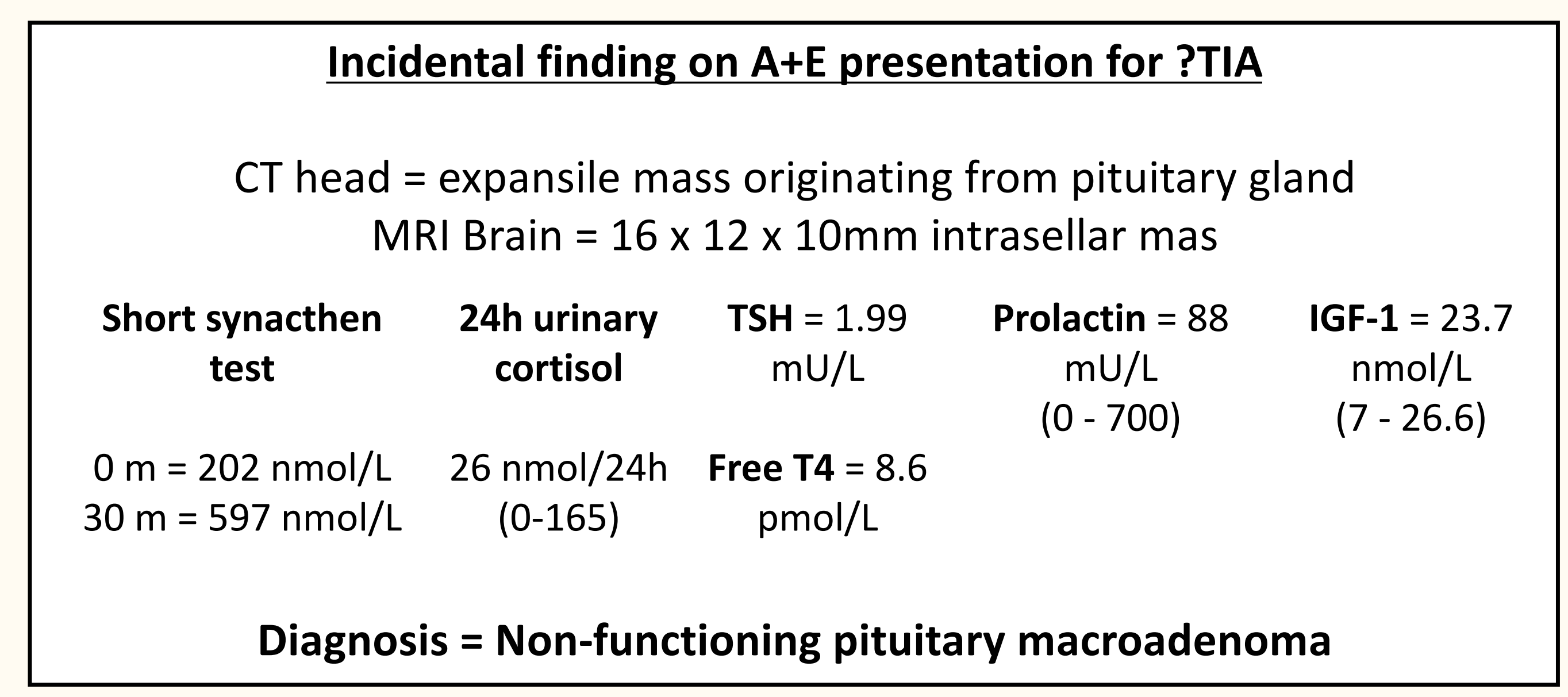

\section{Discussion}

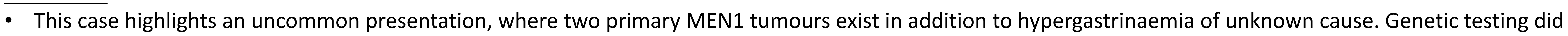
not identify the MEN1 mutation, suggesting she may be a MEN1 phenocopy.

- MEN1 can occur through familial inheritance or occur sporadically, where there is no family history of MEN1. Diagnosis is achieved by meeting one of three criteria: clinical, familial or genetic ${ }^{1}$ (see Figure 1 ).

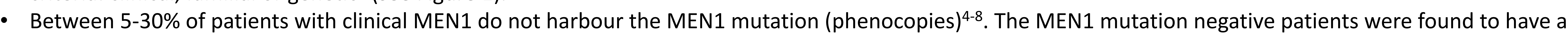
higher age of MEN1 diagnosis, age related penetrance of the first tumour and better overall survival compared to MEN1 mutation positive cases ${ }^{2}$.

- There are suggestions that MEN1 phenocopies have a MEN1 mimicking syndrome, where mutations exist outside of the MEN1 coding region $4,7,8$.

- Screening MEN1 phenocopies can be challenging. Clinically diagnosed MEN1 patients receive annual biochemical and radiological investigation, which are extended to first degree relatives. This monitoring has a cost burden and can cause considerable anxiety. Consensus guidelines support annual screening for relatives of MEN1 phenocopies, however its clinical value remains up for debate ${ }^{1,2}$.

\section{Conclusion}

This case highlights an unusual history of suspected MEN1. The patient qualifies for diagnosis of MEN1 on clinical grounds, although the negative finding for

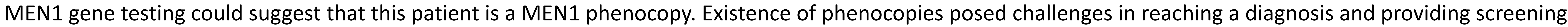
for family members. MEN1 phenocopies may have a milder clinical course than MEN1 mutation positive patients, but this area requires further study.

1. Thakker RV N Newey P, Walls GV, Bilizikian J, Dralle $\mathrm{H}$, Ebeling PR, et al. Clinical practice guidelines for multiple endocrine neoplasia type 1 (MEN1). J Clin Endocrinol

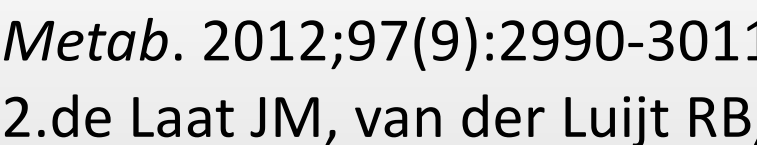

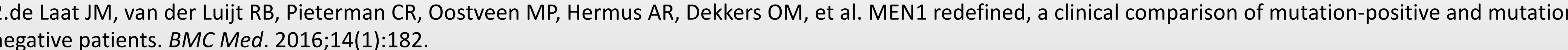

3.Thakker RV. Multiple Endocrine Neoplasia Type 1. In: De Groot L, Jameson J, editors. Endocrinology. 6th ed. Philadelphia: Elsevier; 2010. p. 2719-471.

4.Lemos MC, Thakker RV. Mult

Hum Mutat. 2008:29(1):22.
5.Georgitsi M, Raitlia A, Karl
Metab. 2007:92(8):3321:5.

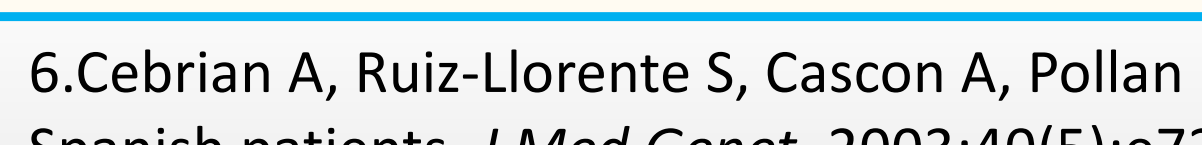
Spanish patients. J Med Genet. 2003;40(5) 7.Sakurai A, Suzuki S, Kosugi S, Okamoto
Clin Endocrinol (Oxf). 2012; $76(4)$ (4):533-9.
8.Tham E, Grandell U, Lindgren E, Toss 6 ,

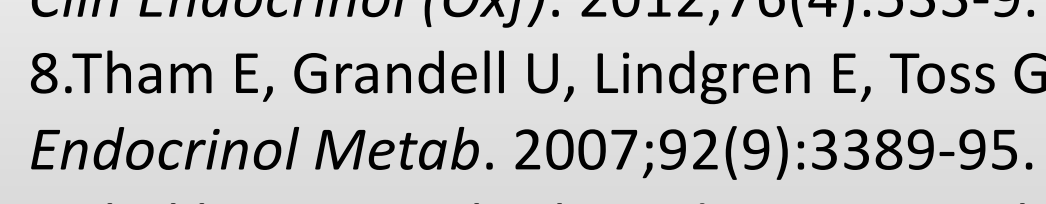

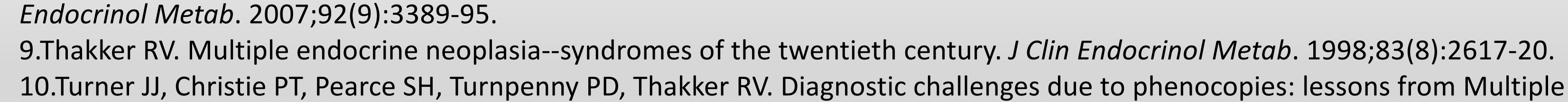
10.Turner JJ, Christie PT, Pearce SH,
Hum Mutat. 2010;31(1):E1089-101

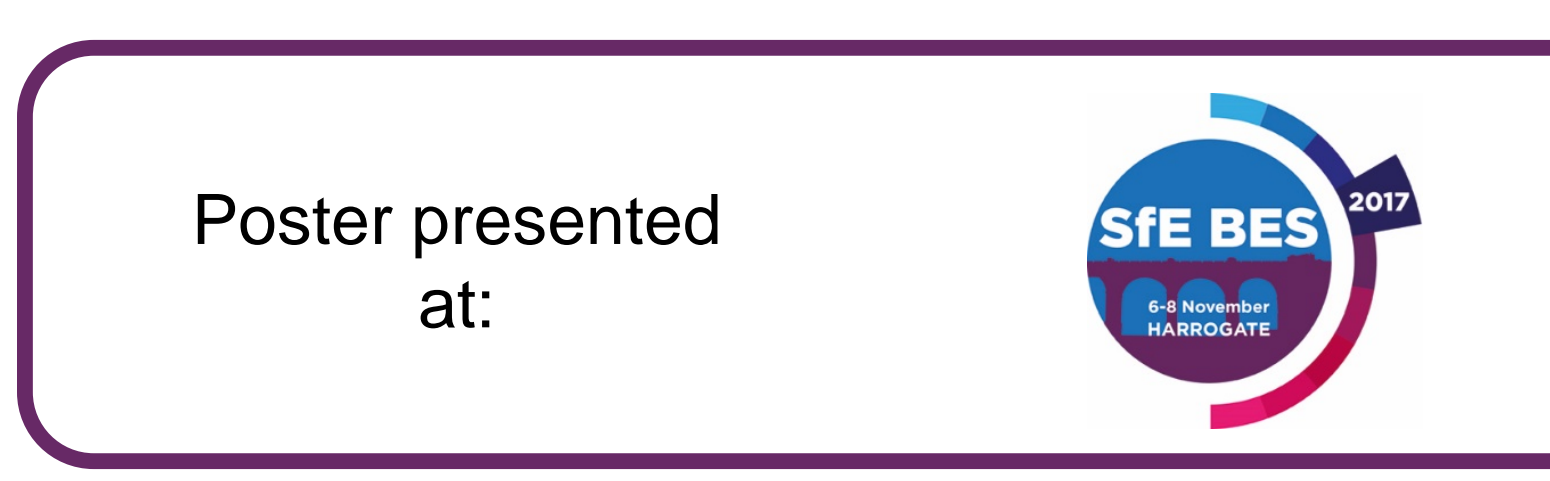

